\title{
Publication rate of abstracts presented at Japan Geriatrics Society Annual Meetings (2011-2012): a retrospective observational study
}

Junpei Komagamine* ${ }^{*}$ and Masaki Kobayashi

\begin{abstract}
Objective: We aimed to determine the publication rate of abstracts presented at Japan Geriatrics Society Annual Meetings. Publication rates were determined by searching for full-text publications up to September 2017 in the MEDLINE database. Factors associated with publication were determined.

Results: In total, 618 abstracts presented at Japan Geriatrics Society Annual Meetings (2011-2012) were included. Of those, 146 (23.6\% [95\% Cl 20.3-27.0\%]) were published in peer-reviewed journals indexed in MEDLINE. The median time to publication was 13.0 months (interquartile range 6.0-25.8 months). More than 90\% were published within 4 years. The publications appeared in 64 different journals, and $87.0 \%$ were published in English-language journals. Multivariable analysis revealed more frequent publication of oral presentations (25.4\% vs $16.9 \%$ of poster presentations; adjusted OR 1.79 [95\% Cl 1.05-3.06]), randomized controlled trials (66.7\% vs 22.8\% for other study designs; adjusted OR 10.79 [95\% Cl 3.02-38.53]) and studies with $n \geq 100$ (28.7\% vs 18.4\% of studies with $n<100$; adjusted OR 1.97 [95\% Cl 1.32-2.95]). Because more than three-fourths of the abstracts presented at Japan Geriatrics Society Annual Meetings remained unpublished within 5 years after the conferences, additional efforts may be needed to promote their publication.
\end{abstract}

Keywords: Annual meetings, Abstracts, Conference, Geriatrics, Publication

\section{Introduction}

A scientific presentation at an annual meeting is considered as an initial method to share novel research findings before their publication in a peer-reviewed journal [1-3]. However, a previous systematic review of 79 studies reported that the average publication rate of abstracts presented at the annual meetings for many specialties was $44.5 \%$ [4]. For recent 19 studies published from 2014 to 2016 , the average publication rate was $41.5 \%$ [5]. Thus, it is estimated that more than half of all abstracts presented at annual meetings are not published after the conference. Therefore, some experts have proposed using

\section{*Correspondence: junpei0919@yahoo.co.jp}

Department of Internal Medicine, National Hospital Organization Tochigi Medical Center, 1-10-37, Nakatomatsuri, Utsunomiya, Tochigi 3208580 , Japan 
Annual Meetings was conducted. The aims of this study were to determine the publication rate of abstracts presented at Japan Geriatrics Society Annual Meetings and to identify factors associated with publication. These meetings were chosen to allow a sufficient time to publication, as more than $95 \%$ of published articles are published within 5 years of initial presentation [4]. All 630 abstracts from these meetings were reviewed. Twelve were excluded ( 3 withdrawn and 9 published more than 6 months before the index annual meetings). The following information was extracted: year of the annual meeting, format, study design, number of authors, affiliation of authors, and sample size of the study.

To evaluate the primary outcome, a publication search was conducted by entering author names as keywords in the MEDLINE database to examine publications from 1946 to September 2017. This search began on October 2, 2017, and was completed on November 2, 2017. Only publications published up to September 2017 were included. Because the deadline for abstract submission to the Japan Geriatrics Society Annual Meeting is approximately 6 months before the conference, publications published more than 6 months before the conference were excluded. A prior study reported good inter-observer reliability for searching publications [11], and the number of abstracts searched was not overly substantial. Therefore, a single investigator (J.K.) performed this search. The name of the first author was used as a keyword to search for the article. If the initial search identified no publications corresponding to the presented abstracts, the name of the second author was used in a search. Abstracts were considered published if a matching full-length article was identified using this search strategy. Based on a previous study, brief reports and research letters were also considered published articles because they are subject to peer review and indexed in MEDLINE [1]. Retrieved publications were compared with the corresponding abstract to ensure that they represented the same work. Only published articles that were nearly identical in terms of target population, hypothesis and study design were judged to be the same work. Articles that included some of the data presented in the abstract (e.g., a smaller cohort) were also regarded as the same work [12]. However, the decision regarding whether the identified article represented the same work as the abstract presented at the annual meeting was difficult for 10 abstracts; these abstracts were discussed, and the judgments resolved by consensus among two authors (J.K. and M.K.). Abstracts were considered unpublished if this search strategy was unable to obtain matching results. Authors of abstracts were not contacted to elicit whether the research had been published in peerreviewed journals. For the identified articles, information on the name of the journal and the publication date were retrieved.

The sample size was determined based on prior similar studies. Two annual meetings were chosen to include more than 400 abstracts because the mean number of abstracts in prior studies was approximately 400 [4]. Descriptive statistics were used for reporting the results. The primary outcome was calculated as the percentage of all included abstracts that were published in peerreviewed journals. The 95\% confidence interval (CI) was also determined for this outcome. For published abstracts, the median time (months) from the annual meeting to publication was calculated. The accumulated number and the proportion of abstracts published every 6 months were also determined. In addition, information on peer-reviewed journals in which the abstracts were published was presented using descriptive statistics. The associations between publication and the following variables were evaluated by univariate analysis using binary logistic regression: year of the annual meeting (2011 or 2012), format (oral or poster), study design (randomized controlled trial or other), number of authors $(\mathrm{n}<3$ or $n \geq 3$ ) [13], affiliation of authors (university-associated or non-university-associated), and sample size of the study $(\mathrm{n}<100$ or $\mathrm{n} \geq 100)$ [14]. A multivariate analysis was also conducted using these variables. These analyses were conducted using Stata version 15 (LightStone, Tokyo, Japan), and the level of statistical significance was $\mathrm{p}<0.05$.

\section{Results}

A total of 618 abstracts (297 in 2011 and 321 in 2012) were evaluated. Of these, 488 (79.0\%) were oral presentations, and $130(21.0 \%)$ were poster presentations. The median number of authors was 5.0 (interquartile range 3.0-7.0). Of all abstracts, 146 (23.6\% [95\% CI 20.3-27.0\%]) were published in a peer-reviewed journal indexed in MEDLINE. The median time to publication was 13.0 months (interquartile range 6.0-25.8 months). Approximately $70 \%$ were published within 2 years, and more than $90 \%$ were published within 4 years (Table 1).

Table 2 shows the characteristics of the abstracts that were associated with publication. In the univariate analysis using binary logistic regression, publication was statistically significantly more frequent for oral presentations $(25.4 \%$ vs $16.9 \%$ for poster presentations; OR 1.67 [95\% CI 1.01-2.76]), randomized controlled trials $(66.7 \%$ vs $22.8 \%$ for other designs; OR 6.78 [95\% CI 2.01-22.86]), and studies with a larger sample size $(28.7 \%$ for $\mathrm{n} \geq 100$ vs $18.4 \%$ for $\mathrm{n}<100$; OR 1.78 [95\% CI 1.22-2.61]). Based on multivariate analysis adjusted for six selected 
Table 1 Distribution of 146 published abstracts by the time of presentation at the 2011 and 2012 Japan Geriatrics Society Annual Meetings to publication

\begin{tabular}{|c|c|c|c|}
\hline \multirow{2}{*}{$\begin{array}{l}\text { Time from annual meeting } \\
\text { presentation to publication }\end{array}$} & \multicolumn{2}{|c|}{ Year of conference $^{a}$} & \multirow{2}{*}{$\begin{array}{l}\text { Accumulated number of } \\
\text { published abstracts }{ }^{\mathrm{a}}, \mathrm{n}(\%)\end{array}$} \\
\hline & 2011 & 2012 & \\
\hline Before the conference ${ }^{b}$ & 7 & 9 & $16(11.0)$ \\
\hline $0-5$ months & 7 & 13 & $36(24.7)$ \\
\hline 6-11 months & 17 & 12 & $65(44.5)$ \\
\hline $12-17$ months & 14 & 10 & $89(61.0)$ \\
\hline 18-23 months & 7 & 6 & $102(69.9)$ \\
\hline 24-29 months & 7 & 6 & 115 (78.8) \\
\hline 30-35 months & 4 & 6 & $125(85.6)$ \\
\hline 36-41 months & 4 & 2 & $131(89.7)$ \\
\hline 42-47 months & 3 & 4 & $138(94.5)$ \\
\hline $48-53$ months & 3 & 1 & $142(97.3)$ \\
\hline 54-59 months & 1 & 3 & $146(100.0)$ \\
\hline After 60 months & 0 & 0 & $146(100.0)$ \\
\hline
\end{tabular}

a Values are the number of published abstracts, with the percentage of the total number of published abstracts in parentheses

${ }^{\mathrm{b}}$ Within 6 months before the annual meeting

Table 2 Characteristics associated with publication of abstracts presented at the 2011 and 2012 Japan Geriatrics Society Annual Meetings

\begin{tabular}{|c|c|c|c|c|}
\hline \multirow[t]{2}{*}{ Characteristics } & \multirow[t]{2}{*}{ Total $^{\mathrm{a}}$} & \multirow{2}{*}{$\begin{array}{l}\text { Number (\%) of published } \\
\text { abstracts }^{\mathrm{a}}\end{array}$} & \multicolumn{2}{|c|}{ Odd ratio ( $95 \%$ confidence interval) $)^{\mathbf{b}}$} \\
\hline & & & Univariate analysis & Multivariate analysis $^{c}$ \\
\hline \multicolumn{5}{|l|}{ Year of the conference } \\
\hline 2011 & 297 & $74(24.9)$ & 1 [reference] & 1 [reference] \\
\hline 2012 & 321 & $72(22.4)$ & $0.87(0.60-1.26)$ & $0.88(0.60-1.30)$ \\
\hline \multicolumn{5}{|l|}{ Presentation format } \\
\hline Poster & 130 & $22(16.9)$ & 1 [reference] & 1 [reference] \\
\hline Oral & 488 & $124(25.4)$ & $1.67(1.01-2.76)^{*}$ & $1.79(1.05-3.06)^{*}$ \\
\hline \multicolumn{5}{|l|}{ Study design } \\
\hline Other ${ }^{d}$ & 606 & $138(22.8)$ & 1 [reference] & 1 [reference] \\
\hline Randomized controlled trial & 12 & $8(66.7)$ & $6.78(2.01-22.86)^{*}$ & $10.79(3.02-38.53)^{* *}$ \\
\hline \multicolumn{5}{|l|}{ Sample size $\mathrm{e}^{\mathrm{e}}$} \\
\hline$<100$ & 299 & $55(18.4)$ & 1 [reference] & 1 [reference] \\
\hline$\geq 100$ & 307 & $88(28.7)$ & $1.78(1.22-2.61)^{*}$ & $1.97(1.32-2.95)^{*}$ \\
\hline \multicolumn{5}{|l|}{ Number of authors } \\
\hline$<3$ & 115 & $24(20.9)$ & 1 [reference] & 1 [reference] \\
\hline$\geq 3$ & 503 & $122(24.3)$ & $1.21(0.74-1.99)$ & $0.98(0.56-1.72)$ \\
\hline \multicolumn{5}{|l|}{ Affiliation of authors } \\
\hline Non-university-associated & 162 & $30(18.5)$ & 1 [reference] & 1 [reference] \\
\hline University-associated & 456 & $116(25.4)$ & $1.50(0.96-2.35)$ & $1.44(0.88-2.35)$ \\
\hline
\end{tabular}

a Values are the number of abstracts, with the percentage of the total number of published abstracts according to subgroups classified by each variable in parentheses

b The level of statistical significance was set at $p<0.05$. Asterisks indicate a significant association between the selected variables and publication; * $p<0.05$,

** $p<0.001$

c Adjusted for the year of the conference, format, study design, number of authors, affiliation of authors, and sample size of the study

$d$ These include observational studies, case reports, case series, simulation analyses, and non-human studies

e Twelve abstracts in which the sample size was not documented were excluded 
variables, oral presentation, randomized controlled trial and larger sample size were the only independent predictive factors to be statistically significantly associated with publication.

Table 3 shows the journals in which the abstracts were published. In total, 146 abstracts presented at the 2011 and 2012 Japan Geriatrics Society Annual Meetings were published in 64 different journals (61 English-language journals and three Japanese-language journals). Of those, 127 abstracts (87.0\%) were published in English-language journals.

\section{Discussion}

This study showed that the overall publication rate of abstracts presented at Japan Geriatrics Society Annual Meetings was $23.6 \%$. More than $90 \%$ of all published abstracts were published within 4 years after the conference. Publication was significantly more frequent for oral presentations, randomized controlled trials, and studies with a larger sample size.

To our knowledge, this study is the first to determine the publication rate of abstracts presented at annual scientific meetings for geriatric medicine. The publication

Table 3 List of journals in which the 146 abstracts presented at the 2011 and 2012 Japan Geriatrics Society Annual Meetings were published

\begin{tabular}{ll}
\hline Journal & $\begin{array}{c}\text { Number of publications } \\
(\mathbf{n}=\mathbf{a}\end{array}$ \\
\hline Geriatr Gerontol Int & $38(26.0)$ \\
Nihon Ronen lgakkai Zasshi [in Japanese] & $17(11.6)$ \\
J Am Geriatr Soc & $8(5.5)$ \\
PLoS One & $4(2.7)$ \\
Arch Gerontol Geriatr & $3(2.1)$ \\
Hiroshima J Med Sci & $3(2.1)$ \\
J Am Med Dir Assoc & $3(2.1)$ \\
Hypertens Res & $3(2.1)$ \\
Behav Brain Res & $2(1.4)$ \\
BMJ Open & $2(1.4)$ \\
Br J Nutr & $2(1.4)$ \\
Cardiovasc Diabetol & $2(1.4)$ \\
Intern Med & $2(1.4)$ \\
J Atheroscler Thromb & $2(1.4)$ \\
J Bone Miner Res & $2(1.4)$ \\
J Hypertens & $2(1.4)$ \\
J Neurol Sci & $2(1.4)$ \\
J Nippon Med Sch & $2(1.4)$ \\
Tokai J Exp Clin Med & $2(1.4)$ \\
Others & $45(30.8)$ \\
\hline D &
\end{tabular}

${ }^{a}$ Values are the number of published abstracts, with the percentage of total publications in parentheses

b These consisted of 45 journals (two Japanese-language journals and 43 English-language journals) rate in the present study was lower than the publication rate in recent studies and a previous systematic review with regard to other specialties outside Japan [1, 4-10] as well as the only Japanese study for the Annual Meeting of the Japanese Orthopaedic Association [2]. Given that author origin (from non-English-language countries vs. from English-language countries) might affect the abstract publication rate $[4,9,15]$, our findings might be limited to Japan and might not be generalizable to authors originating from English-language countries. However, a past systematic review reported an effect of specialties on the publication rate of abstracts [16]. Therefore, it is unclear whether the lower publication rate observed in this study is attributable to the country (Japan), the specialty (geriatrics), or other factors. Further studies of the publication rates of abstracts presented at annual meetings for geriatric medicine in other countries are needed to evaluate the external validity of our findings.

In this study, six variables (year of the annual meeting, format, study design, number of authors, affiliation of authors, and sample size of the study) were evaluated to predict the occurrence of publication. Our findings support the past systematic reviews and recent studies in that oral presentations were more likely to be published than poster presentations $[4,5,10,15-18]$. However, it is unknown why oral presentations are more likely to be published than poster presentations [15], although it is anecdotally noted that a higher-quality study might be selected as an oral presentation by the programme committee $[15,19]$. Our results were also consistent with those of previous studies in showing that randomized controlled trials were more likely to be published than studies with other designs [1,4]. These findings may reflect the emphasis that randomized controlled trials are the gold standard study design for examining the efficacy of treatments [1]. Consistent with a recent study [14], our study showed that a larger sample size $(n \geq 100)$ was significantly associated with more frequent publication. However, given that prior studies have shown conflicting results for the effect of sample size on the likelihood of publication $[1,4,20]$, further studies are needed to evaluate this association.

Prior studies reported that the most frequently cited barriers to abstract publication are lack of time and lack of interest [21-24]. However, it is unclear whether these factors are also barriers to publication among Japanese investigators because all prior studies were conducted outside Japan. Given that more than three-fourths of abstracts presented at Japan Geriatrics Society Annual Meetings were unpublished within 5 years after the conferences, further studies to determine the barriers to publication among Japanese investigators and additional 
efforts to increase the publication rate of abstracts presented at Japan Geriatrics Society Annual Meetings are needed.

\section{Conclusions}

The publication rate of abstracts presented at Japan Geriatrics Society Annual Meetings was 23.6\%. Further studies of scientific meetings for geriatric medicine in other countries are needed to evaluate the external validity of our findings. Because the publication rate of these Japan Geriatrics Society Annual Meetings was lower than the average rate for all previously studied scientific conferences, additional efforts may be needed to increase the rate of publication of abstracts presented at these annual meetings.

\section{Limitations}

Several limitations must be mentioned. First, publication status was determined based on a single database. Furthermore, we did not contact any authors of the abstracts to obtain information about publication. Second, abstracts from only two meetings were included. Furthermore, we evaluated the publication rate of abstracts only for the Japan Geriatrics Society Annual Meetings. Third, factors that might be associated with publication, such as abstract results [4] and abstract quality [25], were not evaluated. Fourth, a prior study reported that there were often various inconsistencies between abstracts presented at annual meetings and matching published articles [26], and for some abstracts included in this study, judging whether they were the same work as the identified articles was difficult. Finally, the possibility of duplicate presentations of the same study at multiple meetings [27] was not investigated.

\section{Abbreviations}

$\mathrm{Cl}$ : confidence interval; OR: odds ratio.

\section{Authors' contributions}

JK conceived and designed the study, collected and analysed the data, and wrote the main paper. MK interpreted and assessed the collected data and wrote the main paper. Both authors read and approved the final manuscript.

\section{Acknowledgements}

Not applicable.

\section{Competing interests}

The authors declare that they have no competing interests.

\section{Availability of data and materials}

All data generated or analysed during this study are included in this published article.

\section{Consent for publication}

Not applicable.

\section{Ethics approval and consent to participate} Not applicable.
Funding

None.

\section{Publisher's Note}

Springer Nature remains neutral with regard to jurisdictional claims in published maps and institutional affiliations.

Received: 2 December 2017 Accepted: 9 January 2018

Published online: 16 January 2018

\section{References}

1. Egloff HM, West CP, Wang AT, Lowe KM, Edakkanambeth Varayil J, Beckman TJ, et al. Publication rates of abstracts presented at the Society of General Internal Medicine Annual Meeting. J Gen Intern Med. 2017:32:673-8. https://doi.org/10.1007/s11606-017-3990-5.

2. Ohtori S, Kubota G, Inage K, Yamauchi K, Orita S, Suzuki M, et al. English publication rate of 3,205 abstracts presented at the Annual Meeting of the Japanese Orthopaedic Association and the Annual Research Meeting of the Japanese Orthopaedic Association. J Orthop Sci. 2013;18:1031-6. https://doi.org/10.1007/s00776-013-0439-5.

3. Fosbøl EL, Fosbøl PL, Harrington RA, Eapen ZJ, Peterson ED. Conversion of cardiovascular conference abstracts to publications. Circulation. 2012;126:2819-25. https://doi.org/10.1161/ CIRCULATIONAHA.112.120535.

4. Scherer RW, Langenberg P, von Elm E. Full publication of results initially presented in abstracts. Cochrane Database Syst Rev. 2007;2:MR000005. https://doi.org/10.1002/14651858.mr000005.pub3.

5. Basilious A, Benavides Vargas AM, Buys YM. Publication rate of abstracts presented at the 2010 Canadian Ophthalmological Society Annual Meeting. Can J Ophthalmol. 2017;52:343-8. https://doi.org/10.1016/j. jcjo.2016.11.033.

6. Walby A, Kelly AM, Georgakas C. Abstract to publication ratio for papers presented at scientific meetings: how does emergency medicine compare? Emerg Med. 2001;13:460-4. https://doi. org/10.1046/j.1035-6851.2001.00262.x.

7. Khajehnoori M, Stupart D, Watters D. Publication rate of general surgery abstracts presented at the Royal Australasian College of Surgeons Annual Scientific Congress. ANZ J Surg. 2017. https://doi.org/10.1111/ans.14103.

8. Macmillan CD, Moore AK, Cook RJ, Pedley DK. Abstract-to-publication ratio for papers presented at scientific meetings: a quality marker for UK emergency medicine research. Emerg Med J. 2007;24:425-6. https://doi. org/10.1136/emj.2007.046078.

9. Chan JWM, Graham CA. Full text publication rates of studies presented at an international emergency medicine scientific meeting. Emerg Med J. 2011;28:802-3. https://doi.org/10.1136/emj.2010.101667.

10. de Meijer VE, Knops SP, van Dongen JA, Eyck BM, Vles WJ. The fate of research abstracts submitted to a national surgical conference: a crosssectional study to assess scientific impact. Am J Surg. 2016;211:166-71. https://doi.org/10.1016/j.amjsurg.2015.06.017.

11. Murrey DB, Wright RW, Seiler JG 3rd, Day TE, Schwartz HS. Publication rates of abstracts presented at the 1993 Annual Academy Meeting. Clin Orthop Relat Res. 1999;359:247-53.

12. $\mathrm{Ng} \mathrm{L}$, Hersey $\mathrm{K}$, Fleshner N. Publication rate of abstracts presented at the annual meeting of the American Urological Association. BJU Int. 2004;94:79-81. https://doi.org/10.1111/j.1464-410X.2004.04905.x.

13. Waldorff FB, Petersen K, Vinther S, Sandholdt H, Siersma V, Andersen JS. Full journal publication of abstracts presented at the Nordic Congress of General Practice in 2009 and 2011. Scand J Prim Health Care. 2017;35:848. https://doi.org/10.1080/02813432.2017.1288820.

14. Udovicich C, Soh B, Law S, Hoe V, Lanfranco D, Perera K, et al. Predictive factors for publication of abstracts at the Royal Australasian College of Surgeons Annual Scientific Congress. ANZ J Surg. 2017. https://doi. org/10.1111/ans.14108.

15. von Elm E, Costanza MC, Walder B, Tramèr MR. More insight into the fate of biomedical meeting abstracts: a systematic review. BMC Med Res Methodol. 2003;3:12. https://doi.org/10.1186/1471-2288-3-12. 
16. Gandhi D, Mclean IRW, Laiyemo AO. Analysis of the publication rate of the abstracts presented at a National Gastroenterology Meeting after 6 years. Digestion. 2016;94:215-21. https://doi.org/10.1159/000450785.

17. Manuck TA, Barbour K, Janicki L, Blackwell SC, Berghella V. Conversion of Society for Maternal-Fetal Medicine abstract presentations to manuscript publications. Am J Obstet Gynecol. 2015;213:405.e1-6. https://doi. org/10.1016/j.ajog.2015.05.020.

18. Williams BR, Kunas GC, Deland JT, Ellis SJ. Publication rates for podium and poster presentations from the American Orthopaedic Foot \& Ankle Society: 2008-2012. Foot Ankle Int. 2017;38:558-63. https://doi. org/10.1177/1071100716688723.

19. Ha TH, Yoon DY, Goo DH, Chang SK, Seo YL, Yun EJ, et al. Publication rates for abstracts presented by Korean investigators at major radiology meetings. Korean J Radiol. 2008;9:303-11. https://doi.org/10.3348/ kjr.2008.9.4.303

20. Castaldi S, Giacometti M, Toigo W, Bert F, Siliquini R. Analysis of full-text publication and publishing predictors of abstracts presented at an Italian public health meeting (2005-2007). BMC Res Notes. 2015;8:492. https:// doi.org/10.1186/s13104-015-1463-7.

21. Bakkum BW, Chapman C. Barriers to peer-reviewed journal article publication of abstracts presented at the 2006-2008 Association of Chiropractic Colleges Educational Conference and Research Agenda Conference Meetings. J Chiropr Educ. 2017;31:20-6. https://doi.org/10.7899/ JCE-14-21.
22. Montané $\mathrm{E}$, Vidal X. Fate of the abstracts presented at three Spanish clinical pharmacology congresses and reasons for unpublished research. Eur J Clin Pharmacol. 2007;63:103-11. https://doi.org/10.1007/ s00228-006-0235-7.

23. Weber EJ, Callaham ML, Wears RL, Barton C, Young G. Unpublished research from a medical specialty meeting: why investigators fail to publish. JAMA. 1998;280:257-9. https://doi.org/10.1001/jama.280.3.257.

24. Sprague S, Bhandari M, Devereaux PJ, Swiontkowski MF, Tornetta P 3rd, Cook DJ, et al. Barriers to full-text publication following presentation of abstracts at annual orthopaedic meetings. J Bone Joint Surg Am. 2003;85-A:158-63.

25. Sawatsky AP, Beckman TJ, Edakkanambeth Varayil J, Mandrekar JN, Reed DA, Wang AT. Association between study quality and publication rates of medical education abstracts presented at the Society of General Internal Medicine Annual Meeting. J Gen Intern Med. 2015;30:1172-7. https://doi org/10.1007/s11606-015-3269-7.

26. Balasubramanian SP, Kumar ID, Wyld L, Reed MW. Publication of surgical abstracts in full text: a retrospective cohort study. Ann R Coll Surg Engl. 2006;88:57-61. https://doi.org/10.1308/003588406X82961.

27. Bhandari M, Patenall V, Devereaux PJ, Tornetta P 3rd, Dirschl D, Leece P, et al. An observational study of duplicate presentation rates between two national orthopedic meetings. Can J Surg. 2005;48:117-22.

\section{Submit your next manuscript to BioMed Central and we will help you at every step:}

- We accept pre-submission inquiries

- Our selector tool helps you to find the most relevant journal

- We provide round the clock customer support

- Convenient online submission

- Thorough peer review

- Inclusion in PubMed and all major indexing services

- Maximum visibility for your research

Submit your manuscript at www.biomedcentral.com/submit 